\section{Relationship between anthropometric nutritional status and functional capacity in older adults living in the community}

\author{
FRANCISCO GUEDE-ROJAS ${ }^{1, \mathrm{a}, \mathrm{e}}$, DANIEL JEREZ-MAYORGA $^{1, \mathrm{a}, \mathrm{e}}$, \\ DAVID ULLOA-DÍAZ ${ }^{2, \mathrm{~b}, \mathrm{e}}$, ADOLFO SOTO-MARTÍNEZ ${ }^{1, \mathrm{a}, \mathrm{d}}$, \\ RODRIGO RAMÍREZ-CAMPILLO ${ }^{3, b, e}$, PAOLA BARBOZA-GONZÁLEZ ${ }^{4, b, e}$, \\ LISSÉ ANGARITA-DÁVILA ${ }^{5, \mathrm{c}, \mathrm{e}}$
}

\section{ABSTRACT}

Background: The functional fitness of older people may be associated with their nutritional status. Aim: To assess the association between of anthropometric measures with functional fitness in older people. Material and Methods: Cross-sectional study conducted in 75 participants aged 65 to 89 years. Body mass index (BMI), waist-to-height ratio (WHtR), fat mass (FM) and skeletal muscle mass index (SMI) were calculated from anthropometric measures. The functional fitness was determined using the Senior Fitness Test battery. Results: BMI and FM indicated obesity, and WHtR indicated cardiometabolic risk in 49\%, $55 \%$ and $83 \%$ of participants, respectively. SMI indicated a low muscle mass in 91\% of females. Performance standards of chair stand, arm curl, 2-min step test and 8 -foot up-and-go tests were met in 1\%,8\%, 1\% and 89\% of participants, respectively. Significant negative correlations were found between 2-min step test and BMI, WHtR and FM ( $r=-0.26,-0.31$ and -0.48 respectively). Back scratch had a negative correlation with BMI $(r=-0.23)$ and SMI ( $r h o=-0.28)$. Significant positive correlations were found between 8-foot up-and-go, WHtR (rho =0.28) and FM (rho = 0.23), and between 2-min step test and SMI (rho =0.28). The coefficient of determination $\left(R^{2}\right)$ between 2-min step test with BMI, WHtR and $F M$ were $0.05,0.08$ and 0.22 , respectively, while the $R^{2}$ between back scratch and $B M I$ was 0.04. Multiple regression models indicated that FM affected the 2-min step test independently of BMI and WHtR (adjusted $R^{2}=0.22$ ), however age and sex negatively influenced these associations. Conclusions: Functional fitness of older adults is influenced by nutritional anthropometric measures, particularly BMI, WHtR and FM for aerobic capacity, and BMI for upper limb flexibility.

(Rev Med Chile 2020; 148: 69-77)

Key words: Aged; Anthropometry; Physical Fitness; Nutritional Status.

\section{Relación entre estado nutricional antropométrico y condición física funcional en adultos mayores independientes}

Introducción: El estado nutricional y la condición física funcional (CFF) pueden estar relacionados en adultos mayores. Objetivo: Analizar la influencia de
${ }^{1}$ Facultad de Ciencias de la Rehabilitación. Carrera de Kinesiología. Universidad Andres Bello, sede Concepción. Concepción, Chile.

${ }^{2}$ Departamento de Ciencias del Deporte y Acondicionamiento Físico. Universidad Católica de la Santísima Concepción. Concepción, Chile.

${ }^{3}$ Laboratory of Human Performance. Quality of Life and Wellness Research Group Department of Physical Activity. Universidad de Los Lagos. Osorno, Chile

${ }^{4}$ Facultad de Educación y Ciencias Sociales. Carrera de Educación Física. Universidad Andres Bello, sede Concepción. Concepción, Chile.

${ }^{5}$ Facultad de Medicina. Escuela de Nutrición y Dietética. Universidad Andres Bello, sede Concepción.

Concepción, Chile.

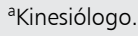

bProfesor de Educación Física.

'Nutricionista.

${ }^{\mathrm{d} M S C \text {. }}$

ePhD.

Trabajo no recibió financiamiento Los autores declaran no tener conflictos de interés.

Recibido el 19 de febrero de 2019, aceptado el 27 de noviembre de 2019.

Corresponding Author: Francisco Guede Rojas. Universidad Andres Bello. Autopista 7100 ConcepciónTalcahuano. Talcahuano, Chile francisco.guede@unab.cl 
medidas antropométricas nutricionales sobre CFF. Material y Método: Estudio transversal realizado en 75 adultos de 65 a 89 años. Las variables antropométricas fueron indice de masa corporal (IMC), razón cintura-talla (RCT), masa adiposa (MA) e indice de masa muscular esquelética (IMME). La evaluación de CFF se efectuó con la batería Senior Fitness Test. Resultados: El IMC y MA indicaron obesidad, $y$ RCT indicó riesgo cardiometabólico en 49\%, 55\% y 83\% de los participantes, respectivamente. IMME indicó una baja masa muscular en $91 \%$ de las mujeres. El estándar de rendimiento para las pruebas sentarse-levantarse, flexión-codo, paso-2-minutos y levantarse-caminar-sentarse se logró en $1 \%, 8 \%, 1 \%$ y $89 \%$ de los participantes, respectivamente. Se encontraron correlaciones significativas negativas entre paso-2-minutos con IMC, RCT y MA $(r=-0.26,-0.31$ y-0.48 respectivamente. La misma asociación se observó entre juntar-manos-espalda con IMC $(r=-0.23)$ e IMME ( $r$ ho = -0.28). Se encontraron correlaciones significativas positivas entre levantarse-caminar-sentarse con RCT (rho=0.28) y MA (rho =0.23), y entre paso-2-minutos con IMME $($ rho $=0.28)$. Los $R^{2}$ entre paso-2-minutos e IMC, RCT y MA fueron 0.05, 0.08 y 0.22 , respectivamente, mientras que el $R^{2}$ entre juntar-manos-espalda e IMC fue 0.04. Los modelos de regresión múltiple indicaron que MA afectó la prueba paso-2-minutos independientemente de IMC y RCT $\left(R^{2}\right.$ ajustado $\left.=0.22\right)$, aunque la edad y sexo afectaron negativamente estas asociaciones. Conclusiones: La CFF de adultos mayores es influenciada por alteraciones evidenciadas por medidas antropométricas nutricionales, particularmente IMC, RCT y MA sobre la capacidad aeróbica, e IMC sobre la flexibilidad de extremidad superior.

Palabras clave: Ancianos; Antropometría; Estado Nutricional.

$\mathrm{E}$ xcess body weight is a global problem that affects $\sim 30 \%$ of the population ${ }^{1}$. Obesity rates have increased in all ages, with high prevalence in elderly and vulnerable socioeconomic groups ${ }^{1}$, increasing the risk of mortality, morbidity and loss of functional capacity ${ }^{2}$.

Due to its relative low cost and simplicity, anthropometry is a fundamental part of the nutritional assessment in older adults ${ }^{3}$. However, beyond traditional measures such as body mass index (BMI) and waist circumference (WC $)^{4}$, the use of waist-to-height ratio (WHtR) has been suggested due to its greater predictive capacity of cardiometabolic risk (CMR $)^{5,6}$. It is important to consider that although these measures help to identify excessive body weight and functional limitation, they do not distinguish body components like fat mass (FM) and muscle mass (MM), which by themselves are also determinants of functionality ${ }^{7,8}$.

Functional fitness (FF) represents the physiological capacity to perform normal everyday activities, safely and independently, without undue fatigue ${ }^{9}$. Thus, FF expressed in terms of strength, endurance, flexibility, and agility-dynamic balan- ce, is essential to preserve the mobility necessary to carry out daily activities 9 . FF tests are determinants of functional capacity in the elderly and therefore, a reduction in their performance usually precedes functional dependence, facilitating consequently its early prevention ${ }^{10,11}$.

Although nutritional and functional status have key associations in advanced age, to date the evidence is not conclusive and more research is required, particularly of alternative measures to $\mathrm{BMI}^{12,14}$. In addition, although for decades the quantification of physical capacity has been recommended as part of a comprehensive nutritional assessment, to date there is no consensus regarding the FF tests that should be included ${ }^{15}$. It is important to consider that aging is a highly heterogeneous process, modulated by genetic, environmental and even stochastic factors ${ }^{16}$, and that the socioeconomic context of each country or region can strongly influence the physical performance of the elderly ${ }^{17,18}$. For these reasons, extrapolation of results from international studies is complex. Considering this background and the scarce literature available in our country, the purpose of this study was to explore the predictive 
association between nutritional status expressed by different anthropometric measures and a battery of FF tests in a sample of Chilean community-dwelling and independent older adults.

\section{Material and Methods}

\section{Participants}

In this pilot cross-sectional study, 75 subjects over 65 years of age ( 19 men and 56 women) were included. The subjects were conveniently recruited from a public health community center under the following inclusion criteria: Independent condition according to Barthel's Index ${ }^{19}$, achieve $\geq 13$ points in the abbreviated Mini-Mental Status Examination (MMSE) ${ }^{20}$ and medical certification to participate in the study. The exclusion criteria were: Disabling sensory alterations, uncontrolled chronic or acute disease and any condition interfering functional independence.

The procedures were conducted in the community center and an informed consent was obtained. The protocols were according to Helsinki Declaration being approved by the Bioethics Committee of Andres Bello University.

\section{Anthropometric measures}

The BMI (weight $[\mathrm{kg}] /$ height $\left[\mathrm{m}^{2}\right]$ ) and WHtR (WC $[\mathrm{cm}] /$ height $[\mathrm{cm}])$ were determined according to $\mathrm{WHO}^{4}$ and Ashwell et al. ${ }^{6}$ respectively. Body weight and height were measured on a scale-stadiometer (Model 2391, Detecto ${ }^{\circledR}$ Scale Company. Webb City, Missouri, USA). WC was measured using a metal tape measure (Rosscraft ${ }^{\circledR}$ Innovation Inc. Surrey, Canada). The FM expressed as body weight percentage was determined according to Gallagher et al. ${ }^{21}$. Finally, as a representative measure of $\mathrm{MM}$, the skeletal muscle mass index (SMI) (appendicular muscle mass $[\mathrm{kg}] /$ height $\left[\mathrm{m}^{2}\right]$ ) was determined, according to EWGSOP ${ }^{7}$. The appendicular muscle mass was calculated according to Baumgartner et al. ${ }^{22}$. The cut-off points for SMI were 7.26 and $5.5 \mathrm{~kg} / \mathrm{m}^{2}$ for men and women, respectively ${ }^{7}$.

\section{Functional fitness (FF)}

The Senior Fitness Test (SFT) is a battery of validated tests that have shown an excellent reliability ${ }^{9}$. The tests performed were: chair stand (lower body strength), arm curl (upper body strength), 2-min step test (aerobic endurance), chair sit-and-reach (lower body flexibility), back scratch (upper body flexibility) and 8-foot upand-go (agility-dynamic balance). The prevalence of cases that reached the recommended standards expressed as cut-off points according to sex and age, was determined for the chair stand, arm curl, 2-min step test and 8-foot up-and-go tests ${ }^{9}$.

\section{Statistical analysis}

The values are reported as mean and standard deviation. The distribution of normality of data was analyzed by Shapiro-Wilk test. The comparative analyses were performed using independent t-test or U Mann-Whitney test, and the correlations were performed by Pearson's $r$ or Spearman's rho coefficients. The cut-off points to categorize the coefficients were: 0.1-0.29 low; 0.3-0.49 moderate and $\geq 0.5$ high $^{23}$.

A predictive analysis was carried out using simple linear regression models (SLRM) for significant $r$ coefficients, also considering homoscedasticity (Levene's test) and independence of the observations (Durbin-Watson's test). The FF tests were considered as dependent variables and anthropometric measures as independent variables. To reconcile units of measurement and verify the models, the variables were normalized as typified $Z$ variables. Finally, two multiple linear regression models (MLRM) were performed. Model "A" was adjusted according to anthropometric measures, and model " $B$ " additionally included age and sex as confounding variables. All analyzes were carried out using IBM SPSS Statistics version 23,0 (IBM Corp., Armonk, NY, USA) $(p<0.05)$.

\section{Results}

Participants' characteristics for the full sample and stratified by sex are summarized in Table 1 . The age range was 65 to 89 years. Body height, weight, FM and SMI differed between sexes $(p<0.05)$. The mean values of BMI and FM for the total sample indicated obesity $(49.3 \%$ and $54.7 \%$, respectively). In addition, WHtR indicated elevated CMR $(82.7 \%)$. In women, the mean value of SMI suggested low MM (91\%). Regarding FF, the performance of the 2-min step test and chair sitand-reach test differed between sexes $(p<0.05)$. For the total sample, the performance standard 
Table 1. Characteristics of the study sample

\begin{tabular}{|c|c|c|c|c|}
\hline & $\begin{array}{c}\text { Total } \\
(n=75) \\
M \pm S D\end{array}$ & $\begin{array}{c}\text { Men } \\
(n=19) \\
M \pm S D\end{array}$ & $\begin{array}{l}\text { Women } \\
(n=56) \\
M \pm S D\end{array}$ & p value \\
\hline Age (y) & $71.9 \pm 5.6$ & $72.5 \pm 6.2$ & $71.8 \pm 5.4$ & 0.616 \\
\hline \multicolumn{5}{|l|}{ Anthropometry } \\
\hline Height (cm) & $1.53 \pm 0.08$ & $1.61 \pm 0.08$ & $1.50 \pm 0.07$ & 0.000 \\
\hline Weight (kg) & $75.4 \pm 15.6$ & $85.1 \pm 14.9$ & $72.2 \pm 14.5$ & 0.001 \\
\hline Body mass index $\left(\mathrm{kg} / \mathrm{m}^{2}\right)$ & $32.0 \pm 5.1$ & $32.7 \pm 4.5$ & $31.8 \pm 5.2$ & 0.520 \\
\hline WHtR & $0.67 \pm 0.09$ & $0.67 \pm 0.06$ & $0.67 \pm 0.09$ & 0.875 \\
\hline Fat mass (\%) & $40.1 \pm 6.2$ & $32.3 \pm 3.0$ & $43.0 \pm 4.5$ & 0.000 \\
\hline $\mathrm{SMI}\left(\mathrm{kg} / \mathrm{m}^{2}\right)$ & $6.0 \pm 3.2$ & $11.4 \pm 0.7$ & $4.2 \pm 0.8$ & 0.000 \\
\hline \multicolumn{5}{|l|}{ Senior Fitness Test } \\
\hline Chair stand (reps/30s) & $9.41 \pm 2.4$ & $9.32 \pm 2.21$ & $9.45 \pm 2.48$ & 0.839 \\
\hline Arm curl (reps/30s) & $10.67 \pm 3.17$ & $11.16 \pm 3.7$ & $10.50 \pm 2.98$ & 0.245 \\
\hline 2-min step test (reps) & $50.88 \pm 19.9$ & $64.79 \pm 16.56$ & $46.16 \pm 18.81$ & 0.000 \\
\hline Chair sit-and-reach (cm) & $-0.41 \pm 5.79$ & $-3.37 \pm 6.78$ & $0.59 \pm 5.1$ & 0.025 \\
\hline Back scratch $(\mathrm{cm})$ & $-10.50 \pm 15.17$ & $-13.32 \pm 19.57$ & $-9.54 \pm 13.44$ & 0.351 \\
\hline 8-foot up-and-go (s) & $8.44 \pm 2.56$ & $7.85 \pm 1.62$ & $8.64 \pm 2.79$ & 0.435 \\
\hline
\end{tabular}

$p<0.05$ Significant difference between sexes; M SD Mean and standard deviation; WHtR Waist-to-height ratio; SMI Skeletal muscle mass index.

of the chair stand, arm curl and 2-min step test was achieved by $1.3 \%, 8 \%$ and $1.3 \%$, respectively, while the standard of the 8 -foot up-and-go test was reached by $89.3 \%$.

All significant correlation coefficients were low or moderate. According to $r$ coefficients the number of repetitions completed in the 2-min step test was inversely correlated with BMI $(r=-0.26)$, $\mathrm{WHtR}(\mathrm{r}=-0.31)$ and FM $(\mathrm{r}=-0.48)$. Moreover, the distance reached in the back scratch test was inversely correlated with BMI $(r=-0.23)$. According to rho coefficients, the 2-min step test was directly correlated with SMI $($ rho $=0.28)$, the back scratch test was inversely correlated with SMI $($ rho $=-0.28)$, and a greater time (less agility) in the 8 -foot up-and-go test was directly correlated with WHtR $($ rho $=0.28)$ and FM $($ rho $=0.23)($ Table 2$)$.

The significance of the SLRM confirmed the observed correlations for $\mathrm{r}$ coefficients. The highest coefficient of determination $\left(\mathrm{R}^{2}\right)$ suggests

Table 2. Correlation coefficients between anthropometric measures and functional fitness

\begin{tabular}{|c|c|c|c|c|}
\hline \multirow[b]{2}{*}{ Functional Fitness } & \multicolumn{4}{|c|}{ Anthropometric measures } \\
\hline & BMI & WHtR & $\mathbf{F M}$ & SMI \\
\hline Chair stand & $-0.19^{\dagger}$ & $-0.19^{\dagger}$ & $-0.12^{+}$ & -0.01 \\
\hline Arm curl & 0.09 & -0.06 & -0.07 & 0.19 \\
\hline 2-min step test & $-0.26^{\dagger *}$ & $-0.31^{+*}$ & $-0.48^{+*}$ & $0.28 *$ \\
\hline Chair sit-and-reach & -0.06 & -0.10 & 0.16 & -0.15 \\
\hline Back scratch & $-0.23^{\dagger *}$ & -0.10 & -0.08 & $-0.28^{*}$ \\
\hline 8-foot up-and-go & 0.20 & $0.28^{*}$ & $0.23^{*}$ & -0.04 \\
\hline
\end{tabular}

${ }^{*} p<0.05 ;{ }^{\dagger}$ Pearson's r coefficient; BMI Body mass index; WHtR Waist-to-height ratio; FM Fat mass; SMI Skeletal muscle mass index. 
that approximately $22 \%$ of the total variability in the 2-min step test was explained by FM. In addition, according to $\beta$ values, it is estimated that the greatest decrease in performance was for the 2-min step test (7.24 repetitions) and that is a function of a unitary increase of WHtR (Table
3). The scatter plots corresponding to each SLRM are presented in Figure 1.

According to MLRM, in model A the significant $\beta$ value indicated that the increase by one percentage in FM determined an average decrease of 1.56 repetitions in the 2 -min step test, indepen-

Table 3. Simple linear regression models between anthropometric measures and functional fitness

\begin{tabular}{|lccccc|}
\hline Outcome & Predictor & $\mathbf{R}^{\mathbf{2}}$ & $\boldsymbol{\beta}$ & $\mathbf{C l}$ & p value \\
\hline 2-min step test & $\mathrm{BMI}$ & 0.05 & -1.01 & $-1.89--0.12$ & 0.026 \\
\hline 2-min step test & $\mathrm{WHtR}$ & 0.08 & -7.24 & $-12.43--2.05$ & 0.007 \\
\hline 2-min step test & $\mathrm{FM}$ & 0.22 & -1.54 & $-2.19--0.89$ & $<0.001$ \\
\hline Back scratch & $\mathrm{BMI}$ & 0.04 & -0.69 & $-1.36--0.01$ & 0.047 \\
\hline
\end{tabular}

$\mathrm{R}^{2}$ Coefficient of determination; $\beta$ Simple linear regression coefficient; $\mathrm{Cl}$ Confidence interval; BMI Body mass index; WHtR Waist-to-height ratio; FM Fat mass.

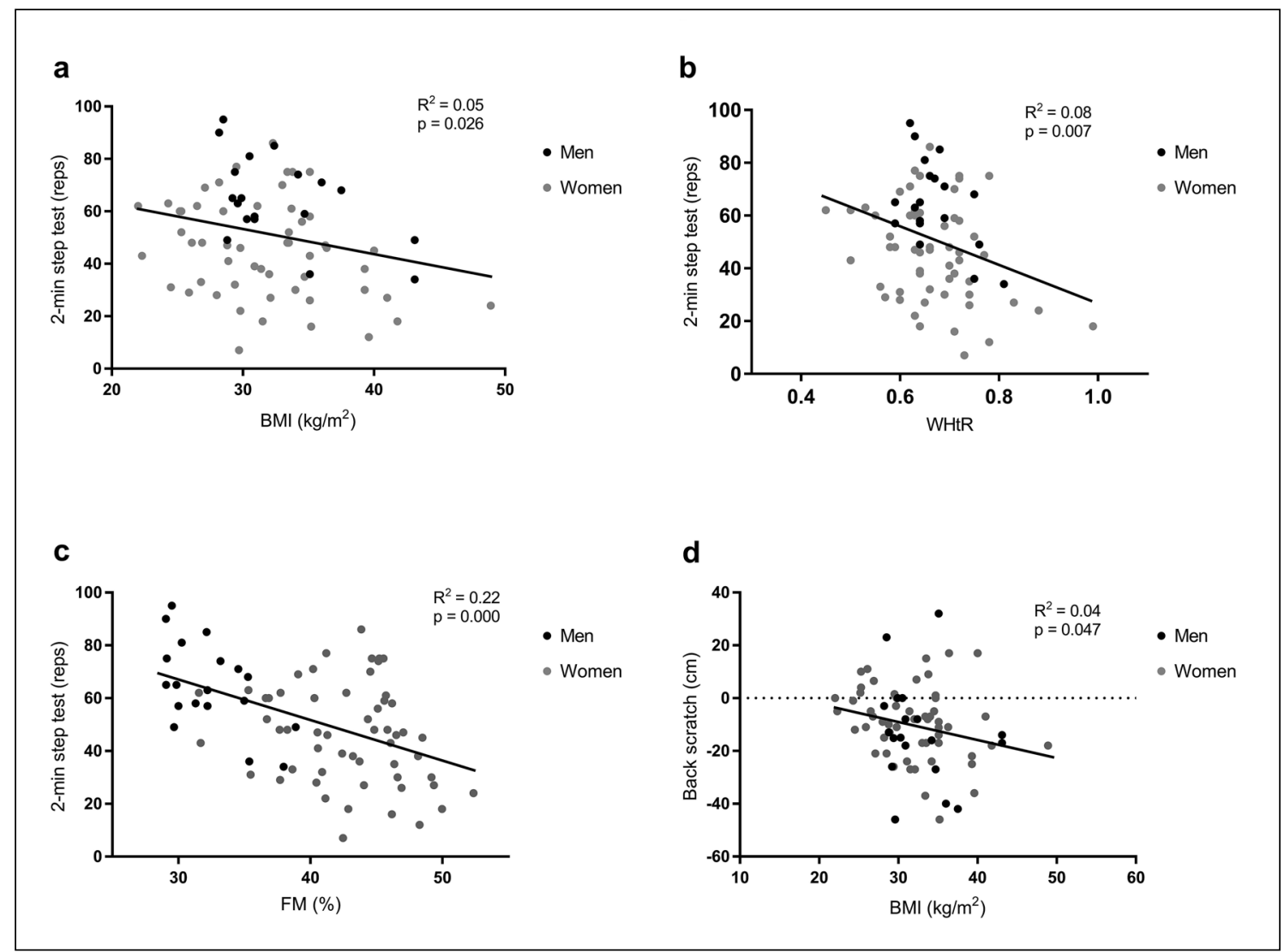

Figure 1. Scatter diagrams for simple linear regression models between body mass index (BMI) and the 2-min step test (a), waist-to-height ratio (WHtR) and the 2-min step test (b), fat mass (FM) and the 2-min step test (c), and BMI and the back scratch test (d). 
Table 4. Multiple linear regression models between anthropometric measures and functional fitness

\begin{tabular}{|c|c|c|c|c|c|c|c|c|c|}
\hline \multirow[b]{2}{*}{ Outcome } & \multirow[b]{2}{*}{ Predictor } & \multicolumn{4}{|c|}{ Model A } & \multicolumn{4}{|c|}{ Model B } \\
\hline & & $\beta$ & $\mathbf{C l}$ & $\begin{array}{c}\mathbf{p} \\
\text { value }\end{array}$ & $\begin{array}{c}\text { Adjusted } \\
\text { R2 }\end{array}$ & $\beta$ & $\mathbf{C l}$ & $\begin{array}{c}\mathbf{p} \\
\text { value }\end{array}$ & $\begin{array}{c}\text { Adjusted } \\
\text { R2 }\end{array}$ \\
\hline \multirow{3}{*}{$\begin{array}{l}\text { 2-min step } \\
\text { test }\end{array}$} & $\mathrm{BMI}$ & 0.93 & $-0.63-2.49$ & 0.239 & 0.22 & -3.57 & $-7.25-0.09$ & 0.056 & 0.28 \\
\hline & $\mathrm{WHtR}$ & -57.31 & $-147.34-32.71$ & 0.208 & & -56.21 & $-143.26-30.84$ & 0.202 & \\
\hline & FM & -1.56 & $-2.38--0.75$ & $<0.001$ & & 4.02 & $-0.25-8.31$ & 0.065 & \\
\hline
\end{tabular}

Model A: adjusted by BMI, WHtR and FM; Model B: adjusted by BMI, WHtR FM, age and sex; $\beta$ Multiple linear regression coefficient; Cl Confidence interval; R2 Adjusted coefficient of determination; BMI Body mass index; WHtR Waist-to-height ratio; FM Fat mass.

dently of BMI and WHtR. In addition, approximately $22 \%$ of the total variability observed in the 2-min step test could be explained by the model. In contrast, model B did not show statistical significance (Table 4).

\section{Discussion}

The results showed a high prevalence of obesity and CMR and reinforce the fact that excess body weight in the elderly population is a global problem $^{1,3,4}$. FM is a metabolically active tissue and its excess is related to inflammation, oxidative stress and reduction of muscular quality due to lipid infiltration, representing as a whole, potential precursors of functional limitation ${ }^{24}$. The progressive reduction of total energy expenditure because of lower levels of physical activity (PA) and lower basal metabolic rate, may explain the increase of $\mathrm{FM}^{25}$. Also, with aging, hormonal alterations can facilitate the accumulation of adipose tissue $e^{25}$. However, interestingly a recent review suggests that obesity can become a protective factor that determine a better survival in elders ${ }^{26}$.

The rapid reduction of MM in older adults, can negatively affect both the glucose regulation and strength, as well as quality of life and level of $\mathrm{PA}^{27}$. The reduction of muscle function can ultimately lead to deficiencies in functional capacity, which in addition to excessive FM, determines a condition of high CMR and disability called sarcopenic obesity $^{28}$. An important deficit of MM was found only in women, and in accordance with previous reports, was higher in men ${ }^{29}$. It has been described that the reduction of $\mathrm{MM}$ in men depends on hormonal factors, PA and cardiovascular disease, while in women it depends basically on PA and $\mathrm{FM}^{30}$. In addition, $\mathrm{MM}$ reduction and muscle function is strongly associated with vitamin D deficiency and overweight in postmenopausal women $^{31}$. Given the strong influence of MM on bone mineral density, the higher prevalence of osteoporosis in women can be explained in part due to lower MM, reinforcing the importance of PA to promote bone mineral density and muscle function $^{32}$.

Anthropometry is a valid method to classify the nutritional status ${ }^{4}$. Nevertheless, given the strong inverse relationship between body height and CMR, WHtR has been suggested ${ }^{5,6}$. In fact, a study conducted in Chile concluded that WHtR had a greater CMR predictive power than BMI, $\mathrm{WC}$ and waist-hip ratio (WHR) in older adults ${ }^{33}$.

Alterations in nutritional status are usually accompanied by poor FF, however, in a study carried out in elders with excess body weight, it was found that subjects with adequate levels of FF did not show an increase in the projected risk of functional loss, whereas those with low performance presented higher risk, suggesting the relevance of $\mathrm{FF}^{10}$. In this study, a high proportion of subjects presented risk of functional limitation due impairment of lower and upper limb strength, as well as aerobic capacity. The standards expressed as cut-off points offered by SFT, provides a criterion about the level of physical performance required for the conservation of functionality, regardless of educational level or ethnicity, which is fundamental as a determinant of healthy aging. It is also important to consider that fitness depends on the levels of PA of the elderly population ${ }^{11}$, as well as socioeconomic factors ${ }^{17}$, including access and quality of health systems ${ }^{18}$. 
Studies have reported that in general, men have greater strength, aerobic capacity, and agility-dynamic balance, while women have greater flexibility $^{34}$. These differences can be explained according to anthropometric characteristics ${ }^{35}$, joint tissue properties ${ }^{36}$, functional mobility ${ }^{37}$, and motor control ${ }^{38}$, proper to each sex. In concordance, in this investigation, men showed greater aerobic capacity and women, greater flexibility of the lower limb, but no differences were observed in strength and agility-dynamic balance.

The correlation analyses indicated that poorer aerobic capacity was related to higher BMI, WHtR and FM, and lower SMI. Poorer flexibility of upper limb is related to higher BMI and SMI, and finally poorer agility-dynamic balance is related to higher WHtR and FM. Then, although the goodness of fit of the SLRM was low, the observed associations suggested the predictive value of BMI, WHtR and FM on aerobic capacity, and the predictive value of BMI on upper limb flexibility. It is worth noting that FM was the measure with the highest predictive reliability and that the strength of this association was preserved independently of the influence of BMI and WHtR. However, it seems that age and sex are confounding variables that can influence these associations, in concordance with other authors ${ }^{39}$.

The low goodness of fit of the models can be attributed to the relatively small sample size, taking as a reference similar studies ${ }^{8,39}$, but it could also be due to the intrinsic variability of the older population, considering the high heterogeneity of the aging process ${ }^{16}$. Furthermore, the potential influence of contextual factors specific to each population cannot be ignored ${ }^{18}$.

Studies focused on independent elders have analyzed the associations between anthropometry and functionality related to daily activities, coinciding about the negative influence of obesity. An et al. found that high BMI negatively influences mobility, muscle function, activities of daily living and gross and fine motor function ${ }^{14}$. Asp et al. showed a strong association between obesity, PA and reduction of mobility ${ }^{12}$, and Nam et al. reported that high BMI in conjunction with high WC, strongly increase the risk of motor disability, even after adjusting for sociodemographic covariates ${ }^{40}$.

Considering that the performance of daily living activities requires different physical capacities, studies have incorporated these components into their analyses. Landi et al. reported that greater MM was favorably associated with physical performance valued by a set of FF tests determinants of aerobic capacity, dynamic balance and lower limb strength ${ }^{8}$. Alcazar et al. by integrating all the SFT tests into a composite global indicator, found that lower FF was strongly related to high prevalence of high BMI, FM, WC and sarcopenic obesity ${ }^{41}$, and Shin et al. found that higher BMI was correlated with longer time to complete 8-m walking at both normal and brisk pace, and that higher FM was associated with poorer physical performance measures (one-leg stance time, timed get-up and-go test, 8-m walking and timed chair sit-to-stand $)^{13}$. Nevertheless, Pereira et al. reported no influence of any category of BMI or FM on the postural balance, although an important limitation recognized by the authors, was that the study did not consider other aspects of $\mathrm{FF}^{42}$.

Nowadays there is still no consensus about the FF tests that should be implemented in a comprehensive geriatric assessment ${ }^{15}$. For this reason, the SFT was considered in order to provide information about a comprehensive battery of relevant FF components ${ }^{9,34}$. The main limitation of this study is related to the cross-sectional design and sampling methodology, which does not allow to extrapolate the results to the population of older adults. Also, the sample is not homogeneous in the number of men and women, which could have influenced the results. Beyond this, the strengths of the research lies in obtaining anthropometric and FF measures currently suggested by the literature, facilitating the analysis of their evolution based on national and international recommendations. In addition, it is important to highlight the fact that few studies incorporate alternative measures to BMI, and as far as we know, the influence of WHtR on FF has not been previously analyzed.

Current results support and complement those of similar previous studies related to functional independence in elders. However, the complexity of the aging process demands more research to fully understand the interactions between these aspects. According to the relative simplicity and value of the considered measures, we propose that they can be included in community health programs aimed to improve the functional independence of older adults, contributing to its planning, evaluation and monitoring. Furthermore, future studies should investigate the effects of different 
approaches aimed at increasing the nutritional status and FF in older adults, and how these may affect the outcomes analyzed in the current study.

Acknowledgment: We thank all the participants of this study for their commitment, dedication and time.

\section{References}

1. Chooi YC, Ding C, Magkos F. The epidemiology of obesity. Metabolism 2019; 92: 6-10.

2. Meadows R, Bower JK. Associations of anthropometric measures of obesity with physical limitations in older adults. Disabil Rehabil 2018; 1-6.

3. Vidal Martins M, Queiroz Ribeiro A, Oliveira Martinho K, Silva Franco F, Danésio de Souza J, Bacelar Duarte de Morais K, et al. Anthropometric indicators of obesity as predictors of cardiovascular risk in the elderly. Nutr Hosp 2015; 31 (6): 2583-9.

4. WHO. Waist Circumference and Waist-Hip Ratio: Report of a WHO Expert Consultation. 2011 [Consulted on January 25, 2019]. Available from: http://apps.who. int/iris/bitstream/handle/10665/44583/?sequence $=1$.

5. Castanheira M, Chor D, Braga JU, de Oliveira Cardoso L, Griep RH, Molina M, et al. Predicting cardiometabolic disturbances from waist-to-height ratio: findings from the Brazilian Longitudinal Study of Adult Health (ELSA-Brasil) baseline. Public Health Nutr 2018; 21 (6): 1028-35.

6. Ashwell M, Gunn P, Gibson S. Waist-to-height ratio is a better screening tool than waist circumference and BMI for adult cardiometabolic risk factors: systematic review and meta-analysis. Obes Rev 2012; 13 (3): 275-86.

7. Cruz-Jentoft AJ, Baeyens JP, Bauer JM, Boirie Y, Cederholm T, Landi F, et al. Sarcopenia: European consensus on definition and diagnosis Report of the European Working Group on Sarcopenia in Older People. Age Ageing 2010; 39 (4): 412-23.

8. Landi F, Onder G, Russo A, Liperoti R, Tosato M, Martone AM, et al. Calf circumference, frailty and physical performance among older adults living in the community. Clinical Nutrition 2014; 33 (3): 539-44.

9. Rikli RE, Jones CJ. Development and validation of criterion-referenced clinically relevant fitness standards for maintaining physical independence in later years. Gerontologist 2013; 53 (2): 255-67.

10. Sardinha LB, Cyrino ES, Dos Santos L, Ekelund U, Santos DA. Fitness but not weight status is associated with projected physical independence in older adults. Age.
2016; 38 (54): https://doi.org/10.1007/s11357-016-99114.

11. Valdés-Badilla P, Concha-Cisternas $Y$, Guzmán-Muñoz E, Ortega-Spuler J, Vargas-Vitoria R. Valores de referencia para la batería de pruebas Senior Fitness Test en mujeres mayores chilenas físicamente activas. Rev Med Chile 2018; 146 (10): 1143-50.

12. Asp M, Simonsson B, Larm P, Molarius A. Physical mobility, physical activity, and obesity among elderly: findings from a large population-based Swedish survey. Public Health 2017; 147: 84-91.

13. Shin H, Liu PY, Panton LB, Ilich JZ. Physical performance in relation to body composition and bone mineral density in healthy, overweight, and obese postmenopausal women. J Geriatr Phys Ther 2014; 37 (1): 7-16.

14. An R, Shi Y. Body weight status and onset of functional limitations in US middle-aged and older adults. Disabil Health J 2015; 8 (3): 336-44.

15. Russell MK. Functional assessment of nutrition status. Nutr Clin Pract 2015; 30 (2): 211-8.

16. Gladyshev VN. Aging: progressive decline in fitness due to the rising deleteriome adjusted by genetic, environmental, and stochastic processes. Aging Cell 2016; 15 (4): 594-602.

17. Stringhini S, Carmeli C, Jokela $M$, Avendaño $M$, McCrory C, d'Errico A, et al. Socioeconomic status, non-communicable disease risk factors, and walking speed in older adults: multi-cohort population based study. BMJ 2018; 360: k1046.

18. Theou O, Brothers TD, Rockwood MR, Haardt D, Mitnitski A, Rockwood K. Exploring the relationship between national economic indicators and relative fitness and frailty in middle-aged and older Europeans. Age Ageing 2013; 42 (5): 614-9.

19. Mahoney FI, Barthel DW. Functional evaluation: The Barthel Index. Md State Med J 1965; 14: 61-5.

20. Muñoz Silva CA, Rojas Orellana PA, Marzuca-Nassr GN. [Functional geriatric assessment in primary health care]. Rev Med Chile 2015; 143 (5): 612-8.

21. Gallagher D, Heymsfield SB, Heo M, Jebb SA, Murgatroyd PR, Sakamoto Y. Healthy percentage body fat ranges: an approach for developing guidelines based on body mass index. Am J Clin Nutr 2000; 72 (3): 694-701.

22. Baumgartner RN, Koehler KM, Gallagher D, Romero L, Heymsfield SB, Ross RR, et al. Epidemiology of sarcopenia among the elderly in New Mexico. Am J Epidemiol 1998; 147 (8): 755-63.

23. Cohen J. Statistical power analysis for the behavioral sciences. Second edition. Lawrence Erlbaum Associates, New York. 1988. 
24. Addison O, LaStayo PC, Dibble LE, Marcus RL. Inflammation, aging, and adiposity: implications for physical therapists. J Geriatr Phys Ther 2012; 35 (2): 86-94.

25. Villareal DT, Apovian CM, Kushner RF, Klein S. Obesity in older adults: technical review and position statement of the American Society for Nutrition and NAASO, The Obesity Society. Obesity Res 2005; 13 (11): 1849-63.

26. Curcio F, Sasso G, Liguori I, Ferro G, Russo G, Cellurale $\mathrm{M}$, et al. The reverse metabolic syndrome in the elderly: Is it a "catabolic" syndrome? Aging Clin Exp Res 2018; 30 (6): 547-54.

27. Casals C, Suárez-Cadenas E, Estébanez Carvajal FM, Aguilar Trujillo MP, Jiménez Arcos MM, Vázquez Sánchez MÁ. Relación entre calidad de vida, actividad física, alimentación y control glucémico con la sarcopenia de adultos mayores con diabetes mellitus tipo 2. Nutr Hosp 2017; 34 (5): 1198-204.

28. Batsis JA, Villareal DT. Sarcopenic obesity in older adults: aetiology, epidemiology and treatment strategies. Nat Rev Endocrinol 2018; 14 (9): 513-37.

29. Janssen I, Heymsfield SB, Wang Z, Ross R. Skeletal muscle mass and distribution in 468 men and women aged 18-88 yr. J Appl Physiol 2000; 89 (1): 81-8.

30. Baumgartner RN, Waters DL, Gallagher D, Morley JE, Garry PJ. Predictors of skeletal muscle mass in elderly men and women. Mech Ageing Dev 1999; 107 (2): 12336.

31. Gimigliano F, Moretti A, de Sire A, Calafiore D, Iolascon G. The combination of vitamin D deficiency and overweight affects muscle mass and function in older post-menopausal women. Aging Clin Exp Res 2018; 30 (6): 625-31.

32. Watson SL, Weeks BK, Weis LJ, Harding AT, Horan SA, Beck BR. High-Intensity Resistance and Impact Training Improves Bone Mineral Density and Physical Function in Postmenopausal Women With Osteopenia and Osteoporosis: The LIFTMOR Randomized Controlled Trial. J Bone Miner Res 2017; 33 (2): 211-20.

33. Koch E, Romero T, Manríquez L, Taylor A, Román C, Paredes M, et al. Razón cintura-estatura: Un mejor predictor antropométrico de riesgo cardiovascular y mortalidad en adultos chilenos. Nomograma diagnóstico utilizado en el Proyecto San Francisco. Rev Chil Cardiol 2008; 27 (1): 23-35.

34. Sardinha LB, Santos DA, Marques EA, Mota J. Criterion-referenced fitness standards for predicting physical independence into later life. Exp Gerontol 2015; 61: 142-6.

35. Perissinotto E, Pisent C, Sergi G, Grigoletto F, Enzi G, Group IW. Anthropometric measurements in the elderly: age and gender differences. Br J Nutr 2002; 87 (2): 177-86.

36. Morse CI. Gender differences in the passive stiffness of the human gastrocnemius muscle during stretch. Eur J Appl Physiol 2011; 111 (9): 2149-54.

37. Zunzunegui M, Alvarado B, Guerra R, Gómez J, Ylli A, Guralnik J, et al. The mobility gap between older men and women: the embodiment of gender. Arch Gerontol Geriatr 2015; 61 (2): 140-8.

38. Johnson ST, Kipp K, Hoffman MA. Spinal motor control differences between the sexes. Eur J Appl Physiol 2012; 112 (11): 3859-64.

39. Danielewicz AL, Barbosa AR, Del Duca GF. Nutritional status, physical performance and functional capacity in an elderly population in southern Brazil. Rev Assoc Med Bras 2014; 60 (3): 242-8.

40. Nam S, Kuo Y, Markides KS, Al Snih S. Waist circumference (WC), body mass index (BMI), and disability among older adults in Latin American and the Caribbean (LAC). Arch Gerontol Geriatr 2012; 55 (2): e40-e7.

41. Alcazar J, Vila S, Pedrero R, Gómez A, Espino L, Gusi N, et al. A novel functional fitness score and its association with obesity status in non-institutionalized males and females aged 65 or over: The exernet multicenter study. Eur J Hum Mov 2016; 37: 56-73.

42. Pereira C, da Silva RA, de Oliveira MR, Souza RD, Borges RJ, Vieira ER. Effect of body mass index and fat mass on balance force platform measurements during a one-legged stance in older adults. Aging Clin Exp Res 2018; 30 (5): 441-7. 